\title{
Mental practice for chronic pain in people with spinal cord injury: a systematic review protocol
}

\author{
Emmanuelle Opsommer ${ }^{1,2} \cdot$ Natalya Korogod $^{1}$ \\ ${ }^{1}$ School of Health Sciences (HESAV), University of Applied Sciences and Arts Western Switzerland (HES-SO), Lausanne, Switzerland, ${ }^{2}$ Bureau \\ $d^{\prime}$ Echanges des Savoirs pour des praTiques exemplaires de soins (BEST): a Joanna Briggs Institute Centre of Excellence, Lausanne, Switzerland
}

Review question/objective: The primary objective of this systematic review is to identify the effects of mental practice (MP) interventions on chronic neuropathic and nociceptive pain and motor function recovery in individuals after spinal cord injury $(\mathrm{SCl})$. Where possible, this review will also describe the optimal type and dosage (i.e. frequency, intensity and duration) of MP interventions for patients with $\mathrm{SCl}$.

Keywords Mental practice; motor imagery; pain; rehabilitation; spinal cord injury

JBI Database System Rev Implement Rep 2017; 15(8):2004-2012.

\section{Background}

pinal cord injury (SCI) is a lesion of the spinal cord, including the cauda equina, affecting its structural and functional integrity. It results either in temporary or permanent muscle paralysis, sensory loss and autonomic dysfunction below the level of injury. ${ }^{1}$ The neural control of sensorimotor, ${ }^{2}$ autonomic, ${ }^{3-5}$ bowel and bladder functions ${ }^{6,7}$ are compromised and SCI is often complicated by pain. ${ }^{8}$ Indeed, pain is a common complication which can be related to the effects of the spinal injuries or to pre-existing conditions. ${ }^{1,8,9}$

Chronic pain, which is pain that persists for months or longer, is a severe consequence of SCI, whereby half to two-thirds of the individuals with SCI report the presence of pain. ${ }^{10-13}$ This pain seems to be related to poorer rehabilitation outcomes and may have a significant impact on activities of daily living, emotional function and quality of life. ${ }^{9,14}$ Some studies, which were discussed in a review by Ullrich, ${ }^{15}$ even suggest that the impact of pain can be greater than the impact of the injury itself in people with chronic pain after SCI. The most common pain types are nociceptive and neuropathic pain. $1,13,16,17$ Nociceptive pain is due to the activation of nociceptors and arises from actual or threatened damage to

Correspondence: Emmanuelle Opsommer,

emmanuelle.opsommer@hesav.ch

There is no conflict of interest in this project.

DOI: 10.11124/JBISRIR-2016-003149 non-neural tissue. ${ }^{18}$ Nociceptive pain often occurs in shoulders, wrists and back due to overuse. ${ }^{13,16,19,20}$ For pain arising as a direct consequence of a lesion or disease affecting the somatosensory system, the resulting condition is referred to as neuropathic pain. ${ }^{21}$ Neuropathic pain is classified relative to the neurological level of injury (NLI). Within the dermatome of the NLI and/or within the three dermatomes below this level, pain is referred to as "at-level" SCI (neuropathic) pain. Pain arising from more than three dermatomes below the dermatome of the NLI is referred to "below-level" SCI (neuropathic) pain. ${ }^{22}$ Neuropathic pain is thought to be a central mechanism (below-level SCI pain) and/or due to nerve root damage (at-level SCI pain). ${ }^{1,22}$ Pain taxonomies are available for SCI, differentiating nociceptive, neuropathic (at- and below-level) and other or unknown pain. ${ }^{22}$

The management of chronic pain after SCI is very challenging. ${ }^{10}$ Recent reviews conclude that there is a lack of evidence on the impact of both pharmacological and non-pharmacological treatments. ${ }^{23,24}$ Other reasons for the lack of success are the multiple mechanisms involved in SCI neuropathic pain and the fact that those are not completely understood. ${ }^{1}$ In addition to biomedical changes due to SCI, psychosocial factors such as cognition, coping behavior and social support may play a major role in the perceived intensity and impact of pain. ${ }^{25,26}$ In clinical practice, pharmacological treatment seems to prevail despite some patients' wishes for nonpharmacological treatments. $^{27}$ 
Among non-pharmacological treatments for pain, studies have identified the contribution of the motor cortex stimulation, ${ }^{28-31}$ which could promote reestablishment and activity-dependent plasticity of the disrupted or altered after SCI sensorimotor loop. ${ }^{32,33}$ One of the techniques that might stimulate these structural and functional reorganizations in the brain is mental practice (MP). ${ }^{34,35}$

Mental practice is defined as a cognitive training method by which the subject mentally repeats a gesture (or movement) to improve its performance. $^{36,37}$ The motor imagery (MI) is the mental representation of movement without any body movement or without any peripheral muscle activation. $^{38}$

The MP of a movement without its execution can be carried out from two perspectives: external (third person) or internal (first person). The third-person perspective is an imagery, where a "person views him-or herself from the perspective of an external observer" ${ }^{38(p .945)}$ (e.g. seeing him/herself performing the imagined movement). It is considered to be mainly visual in nature. The first-person perspective requires the person to imagine "being inside his/her

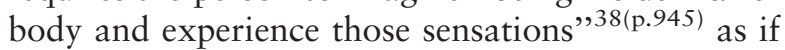
he/she was performing the movement. Therefore, internal (first person) imagery can include both visual and kinesthetic component. ${ }^{38,39}$

Imagery capacity may differ between healthy individuals ${ }^{40}$ as well as in persons with neurological deficits. ${ }^{41}$ Therefore, it could be important to test it before performing MP. ${ }^{38}$ Several tools are used to assess the imagery ability, for example, the Movement Imagery Questionnaire (MIQ), ${ }^{42}$ the MIQRevised, Second Edition (MIQ-RS) ${ }^{43}$ and the Vividness of MIQ (VMIQ), ${ }^{44}$ which are formulated for healthy subjects; and the Kinesthetic and Visual Imagery Questionnaire (KVIQ), ${ }^{45}$ which is adapted more for individuals with disabilities. ${ }^{38}$

The MP, when combined with physical practice, is recognized to have positive effects on motor performance and learning ${ }^{39}$ in healthy subjects, ${ }^{46,47}$ in sportsmen ${ }^{48}$ as well as in people with some neurological disorders like stroke ${ }^{36,49}$ and SCI. ${ }^{50,51} \mathrm{~A}$ number of repetitions are needed to learn a new gesture and to encode it in procedural memory. Magnetic resonance imaging studies have demonstrated that there is a large overlap between brain areas active during $\mathrm{MI}$ and movement itself. ${ }^{35,52-54}$ For example, such brain regions are shown to be involved in both processes of movement imagery and execution: the prefrontal, premotor, supplementary motor and cingulate cortex as well as cerebellum and basal ganglia. ${ }^{55,56}$ The primary motor cortex activation degree during MP is still under debate. ${ }^{55,57-59}$ In addition, positron emission tomography imaging of learning a motor task by MP shows similar cortical changes to those observed after physical training in the same foot movement tasks in healthy subjects. ${ }^{60}$

Following SCI, the cerebral structures involved in $\mathrm{MI}$ and movement execution remain intact but reshaped. ${ }^{41,61}$ The amount of central cortical reorganization is not only connected to the duration of sensory input deprivation or/and overuse, but also to the chronic pain duration and intensity. ${ }^{39,62,63}$ Alternatively, it may be also that in SCI subjects the disrupted cortical proprioceptive representation as a cause of mismatch between motor output and sensory feedback ${ }^{62}$ leads to the pain experience. ${ }^{64}$ Therefore, MP in people with pain is aimed at correcting this mismatch and normalizing complex interactions between mental body representation, sensori-motor integration, nociception and pain.

Until now, the effect of MP on neuropathic pain in SCI patients remains unclear. The studies show heterogeneous results: either reduction in pain ${ }^{34,62}$ or increase in pain, ${ }^{65}$ or no effect. ${ }^{66}$ There could be many reasons for these discrepancies.

One aspect that may influence therapeutic outcome of the pain treatment could be related to the patient's perception of pain and his expectations from treatment, which could be influenced by such factors as depression, poor coping skills, pain catastrophizing and other social stressors. ${ }^{67}$

Another aspect is related to the treatment methodology itself. It is still not clear, for clinical practice, which interventions are more effective and which outcomes are better. For example, MP is often applied in combination with other therapeutic modalities, such as physical exercise, virtual reality, brain-computer interface and mirror therapy. Therefore, in some cases, the contribution of each modality remains unclear. In addition, there are also different intervention procedures (guided imagery, visual cue-based imagery, external or internal perspective), outcome measures (various pain questionnaires: Visual Analog Scale [VAS], Numerical Rating Scale [NRS] etc.) and MI ability parameters 
(vividness, effort and speed) that exist across the studies, which makes it difficult to compare and determine the best practice for pain treatment.

After a preliminary search in JBI Database of Systematic Reviews and Implementation Reports, Cochrane Library, PubMed, Campbell Library, DARE, Trip, NICE, BestBets and Bandolier databases, we did not find any exhaustive systematic review that synthesized all relevant studies and evaluated the efficacy of MP on chronic neuropathic and nociceptive pain in individuals after SCI.

Therefore, in this systematic review, we aim to identify both therapeutic benefits of MP for pain management and motor function recovery in SCI people. Where possible, this review will also describe the optimal type and dosage (i.e. frequency, intensity and duration) of MP interventions for patients with SCI.

\section{Inclusion criteria}

Types of participants

The current review will consider studies that include adult patients (18 years and over) with a clinical diagnosis of SCI that did not necessarily need to be confirmed using imaging studies:

- Traumatic or non-traumatic

- Complete or incomplete: according to the American Spinal Injuries Association Impairment Scale (AIS), complete lesions are defined as AIS A and incomplete are defined as AIS B, AIS C, AIS D or AIS E; ${ }^{68}$ according to the International Standards for Neurological Classification of SCI (ISNCSCI), the term "complete injury" is used when "there is an absence of sensory and motor function in the lowest sacral segments (S4-S5) (i.e. no sacral sparing)" ${ }^{19}(\mathrm{p} .537)$ and the term "incomplete injury" is used when "there is preservation of any sensory and/or motor function below the neurological level that includes the lowest sacral segments S4-S5 (i.e. presence of sacral sparing)"

- Without or with acute, sub-acute or chronic (ator below-level) pain

- All ISNCSCI levels ${ }^{69}$

- Any time after a SCI.

\section{Types of interventions}

The MP intervention can be given as an independent intervention, added to therapy (e.g. using a taped instruction) or embedded in therapy (e.g. usual care, or usual physiotherapy or occupational therapy treatment). Both perspectives of movement representations will be taken into account: first person (visual representation) and third person (both visual representation and kinesthetic sensations). The intervention in the comparator group should allow the assessment of possible effects of the MP intervention. Examples of comparators are MP versus no intervention, MP versus conventional intervention, MP versus placebo MP (e.g. counting backward by sevens, mentally manipulating a three-dimensional object), and MP in individuals with pain compared to MP in individuals without pain.

\section{Outcomes}

The primary outcomes are those related to pain ${ }^{70}$ and will include:

- Pain before, during and/or after movement imagery assessed with, for example, the VAS, NRS, Brief Pain Questionnaire, Basic Pain Data Set, seven-point Guy/Farrar Patient Global Impression Change scale, scales for neuropathic pain and scale for emotional functioning. ${ }^{70,71}$

- Duration of pain relief and/or time to return to pre-treatment pain.

Secondary outcomes will consider following measures:

- Motor function and activity/disability related outcomes, for example, the Motor Assessment Scale, the Capacity of the Arm and Hand test or the Graded and Redefined Assessment of Strength, Sensibility and Prehension. ${ }^{71}$

Further analysis of MI interventions will be done by a comparison of cortical activity during actual and imagined movement, using such techniques as functional magnetic resonance imaging, positron emission tomography, magnetoencephalography and/or transcranial magnetic stimulation. Therefore, additional outcomes that we will consider will be neurophysiological changes associated with primary somatosensory and motor cortex activities as well as motor output system (e.g. motor evoked potentials and motor thresholds).

\section{Types of studies}

The current review will consider both experimental and epidemiological study designs, including randomized controlled trials, non-randomized controlled trials, quasi-experimental studies, before and after studies, prospective and retrospective cohort studies, 
case-control studies and analytical cross-sectional studies for inclusion. This review will also consider descriptive epidemiological study designs, including case series, individual case reports and descriptive cross-sectional studies for inclusion.

\section{Search strategy}

The search strategy aims to find both published and unpublished studies. A three-step search strategy will be utilized in this review. An initial limited search of PubMed and CINAHL will be undertaken followed by an analysis of the text words contained in the title and abstract, and of the index terms used to describe the article. A second search using all identified keywords and index terms will then be undertaken across all included databases. Third, the reference lists of all identified reports and articles will be searched for additional studies. Studies published in English, French and German will be considered for inclusion in this review. No restrictions will be made regarding the year of publication.

Studies in another language that have not been translated into English, French or German will be excluded.

The databases to be searched include: Bandolier, BestBETS, BioMed Central, CINAHL, Cochrane Central Register of Controlled Trials, Embase, PubMed, PsiTri, PsycINFO, MedNar, OTseeker and PEDro.

PubMed search syntax will be used as the basis for all search strategies, using Medical Subject Headings and keywords with Boolean operators. The syntax will consist of several search themes intersected by the Boolean term "AND".

Database individual search strategies will be developed for each database to take into account any differences in thesaurus terminology and indexing.

The search for unpublished studies and conference proceedings will be performed to reveal additional gray literature and unpublished studies. It will include: Australian Clinical Trial Registry, dissertation abstracts and conference proceedings research, ClinicalTrials.gov, Current Controlled Trials, Google Scholar, ProQuest Dissertations and Theses, MedNar, Worldcat and Open Grey (http://www.open grey.eu/) without language restrictions.

Hand searching of relevant journals (e.g. Clinical Rehabilitation, Disability and Rehabilitation, Neurorehabilitation and Neural Repair, Spinal Cord) will be performed.
Full-text articles of studies retrieved in the search will be assessed for relevance against the inclusion and exclusion criteria. Two reviewers will conduct this assessment independently using the Joanna Briggs Institute System for the Unified Management, Assessment and Review of Information (JBISUMARI). Any disagreements that arise between the two reviewers will be resolved through discussion with a third designated reviewer.

Bibliographic details of the studies will be downloaded or manually entered into an Endnote database (Endnote X8) Clarivate Analytics, Philadelphia, PA, USA.

Initial keywords to be used will be: Spinal Cord Injury OR Spinal Cord Injuries OR Spinal Cord Ischemia OR Paraplegia OR Quadriplegia AND Imagery OR Imagination OR Mental Practice OR Cognitive rehearsal OR Guided Imagery OR Motor Imagery.

\section{Assessment of methodological quality}

Papers selected for retrieval will be assessed by two independent reviewers for methodological validity prior to inclusion in the review using standardized critical appraisal instruments from JBI-SUMARI. ${ }^{72}$ Any disagreements that arise between the reviewers will be resolved through discussion, or with a third reviewer.

\section{Data extraction}

Quantitative data will be extracted from papers included in the review using the standardized data extraction tool from JBI-SUMARI (Appendix I). The data extracted will include specific details about the interventions, populations, study methods and outcomes of significance to the review question and specific objectives. Where reported, specific information about the frequency, intensity, duration of MP interventions will also be extracted. This will allow the reviewers to describe the optimal dosage required to achieve the benefits from MP interventions. However, one possible limitation can be a lack of detailed information in the literature. Authors of primary studies will be contacted for missing information or to clarify unclear data.

\section{Data synthesis}

Quantitative data will, where possible, be pooled in statistical meta-analysis using JBI-SUMARI. All 
results will be subject to double data entry. Effect sizes expressed as odds ratio (for categorical data) and weighted mean differences (for continuous data) and their $95 \%$ confidence intervals will be calculated for analysis. Heterogeneity will be assessed statistically using the standard Chi-square and also explored using subgroup analyses based on the different study designs included in this review. Where statistical pooling is not possible, the findings will be presented in narrative form, including tables and figures to aid in data presentation where appropriate.

\section{References}

1. Finnerup NB. Pain in patients with spinal cord injury. Pain 2013;154(Suppl 1):S71-6.

2. Dietz V, Muller R. Degradation of neuronal function following a spinal cord injury: mechanisms and countermeasures. Brain 2004;127(Pt 10):2221-31.

3. Tollefsen E, Fondenes O. Respiratory complications associated with spinal cord injury. Tidsskr Nor Laegeforen 2012;132(9):1111-4.

4. Garshick E, Kelley A, Cohen SA, Garrison A, Tun CG, Gagnon $D$, et al. A prospective assessment of mortality in chronic spinal cord injury. Spinal Cord 2005;43(7):408-16.

5. Hagen EM, Rekand T, Gronning M, Faerestrand S. Cardiovascular complications of spinal cord injury. Tidsskr Nor Laegeforen 2012;132(9):1115-20.

6. Hagen EM, Faerestrand S, Hoff JM, Rekand T, Gronning M. Cardiovascular and urological dysfunction in spinal cord injury. Acta Neurol Scand Suppl 2011;124(Suppl.191):71-8.

7. Benevento BT, Sipski ML. Neurogenic bladder, neurogenic bowel, and sexual dysfunction in people with spinal cord injury. Phys Ther 2002;82(6):601-12.

8. Rekand T, Hagen EM, Gronning M. Chronic pain following spinal cord injury. Tidsskr Nor Laegeforen 2012;132(8): 974-9.

9. Sezer N, Akkus S, Ugurlu FG. Chronic complications of spinal cord injury. World J Orthop 2015;6(1):24-33.

10. Finnerup NB, Baastrup C. Spinal cord injury pain: mechanisms and management. Curr Pain Headache Rep 2012;16(3): 207-16.

11. Jensen MP, Truitt AR, Schomer KG, Yorkston KM, Baylor C, Molton IR. Frequency and age effects of secondary health conditions in individuals with spinal cord injury: a scoping review. Spinal Cord 2013;51(12):882-92.

12. van Gorp S, Kessels AG, Joosten EA, van Kleef M, Patijn J. Pain prevalence and its determinants after spinal cord injury: a systematic review. Eur J Pain 2015;19(1):5-14.

13. Michailidou C, Marston L, De Souza LH, Sutherland I. A systematic review of the prevalence of musculoskeletal pain, back and low back pain in people with spinal cord injury. Disabil Rehabil 2014;36(9):705-15.
14. Ataoglu E, Tiftik T, Kara M, Tunc H, Ersoz M, Akkus S. Effects of chronic pain on quality of life and depression in patients with spinal cord injury. Spinal Cord 2013;51(1):23-6.

15. Ullrich PM. Pain following spinal cord injury. Phys Med Rehabil Clin N Am 2007;18(2):217-33; vi.

16. Siddall PJ, McClelland JM, Rutkowski SB, Cousins MJ. A longitudinal study of the prevalence and characteristics of pain in the first 5 years following spinal cord injury. Pain 2003;103(3):249-57.

17. Mahnig S, Landmann G, Stockinger L, Opsommer E. Pain assessment according to the International Spinal Cord Injury Pain classification in patients with spinal cord injury referred to a multidisciplinary pain center. Spinal Cord 2016;54(10):809-15.

18. Loeser JD, Treede RD. The Kyoto protocol of IASP basic pain terminology. Pain 2008;137(3):473-7.

19. Akbar M, Brunner M, Balean G, Grieser T, Bruckner T, Loew M, et al. A cross-sectional study of demographic and morphologic features of rotator cuff disease in paraplegic patients. J Shoulder Elbow Surg 2011;20(7):1108-13.

20. Cardenas DD, Felix ER. Pain after spinal cord injury: a review of classification, treatment approaches, and treatment assessment. PM R 2009;1(12):1077-90.

21. Treede RD, Jensen TS, Campbell JN, Cruccu G, Dostrovsky JO, Griffin JW, et al. Neuropathic pain: redefinition and a grading system for clinical and research purposes. Neurology 2008;70(18):1630-5.

22. Bryce TN, Biering-Sorensen F, Finnerup NB, Cardenas DD, Defrin R, Lundeberg $T$, et al. International spinal cord injury pain classification: part I. Background and description. March 6-7, 2009. Spinal Cord 2012;50(6):413-7.

23. Boldt I, Eriks-Hoogland I, Brinkhof MW, de Bie R, Joggi D, von Elm E. Non-pharmacological interventions for chronic pain in people with spinal cord injury. Cochrane Database Syst Rev 2014;(11):CD009177.

24. Finnerup NB, Attal N, Haroutounian S, McNicol E, Baron R, Dworkin $\mathrm{RH}$, et al. Pharmacotherapy for neuropathic pain in adults: a systematic review and meta-analysis. Lancet Neurol 2015;14(2):162-73.

25. Widerstrom-Noga EG, Felix ER, Cruz-Almeida Y, Turk DC. Psychosocial subgroups in persons with spinal cord injuries and chronic pain. Arch Phys Med Rehabil 2007;88(12): 1628-35.

26. Jensen MP, Moore MR, Bockow TB, Ehde DM, Engel JM. Psychosocial factors and adjustment to chronic pain in persons with physical disabilities: a systematic review. Arch Phys Med Rehabil 2011;92(1):146-60.

27. Lofgren M, Norrbrink C. "But I know what works"-patients' experience of spinal cord injury neuropathic pain management. Disabil Rehabil 2012;34(25):2139-47.

28. Tsubokawa T, Katayama Y, Yamamoto T, Hirayama $T$, Koyama S. Treatment of thalamic pain by chronic motor cortex stimulation. Pacing Clin Electrophysiol 1991;14(1): $131-4$. 
29. Tsubokawa T, Katayama Y, Yamamoto T, Hirayama T, Koyama S. Chronic motor cortex stimulation for the treatment of central pain. Acta Neurochir Suppl (Wien) 1991;52:137-9.

30. Ramachandran VS, McGeoch PD, Williams L. Can vestibular caloric stimulation be used to treat Dejerine-Roussy syndrome? Med Hypotheses 2007;69(3):486-8.

31. Le Dean Y, Brissebrat B, Castel-Lacanal E, De Boissezon X, Marque P. Management of neuropathic central pain by noninvasive brain stimulation and mirror therapy. Ann Phys Rehabil Med 2016;59S:e145.

32. Dunlop SA. Activity-dependent plasticity: implications for recovery after spinal cord injury. Trends Neurosci 2008;31(8):410-8.

33. Tidoni E, Tieri G, Aglioti SM. Re-establishing the disrupted sensorimotor loop in deafferented and deefferented people: The case of spinal cord injuries. Neuropsychologia 2015;79(Pt B):301-9.

34. Soler MD, Kumru H, Pelayo R, Vidal J, Tormos JM, Fregni F, et al. Effectiveness of transcranial direct current stimulation and visual illusion on neuropathic pain in spinal cord injury. Brain 2010;133(9):2565-77.

35. Lotze M, Halsband U. Motor imagery. J Physiol Paris 2006;99(4-6):386-95.

36. Barclay-Goddard RE, Stevenson TJ, Poluha W, Thalman L. Mental practice for treating upper extremity deficits in individuals with hemiparesis after stroke. Cochrane Database Syst Rev 2011;(5):CD005950.

37. Malouin F, Richards CL. Mental practice for relearning locomotor skills. Phys Ther 2010;90(2):240-51.

38. Dickstein R, Deutsch J. Motor imagery in physical therapist practice. Phys Ther 2007;87(7):942-53.

39. Mulder T. Motor imagery and action observation: cognitive tools for rehabilitation. J Neural Transm 2007;114(10): $1265-78$.

40. Isaac AR, Marks DF. Individual differences in mental imagery experience: developmental changes and specialization. $\mathrm{Br}$ J Psychol 1994;85(Pt 4):479-500.

41. Di Rienzo F, Collet C, Hoyek N, Guillot A. Impact of neurologic deficits on motor imagery: a systematic review of clinical evaluations. Neuropsychol Rev 2014;24(2): $116-47$.

42. Hall CR, Pongrac J. Movement imagery: questionnaire. London, Ontario: University of Western Ontario Faculty of Physical Education; 1983.

43. Butler AJ, Cazeaux J, Fidler A, Jansen J, Lefkove N, Gregg M, et al. The Movement Imagery Questionnaire-Revised, Second Edition (MIQ-RS) is a reliable and valid tool for evaluating motor imagery in stroke populations. Evid Based Complement Alternat Med 2012;2012:497289.

44. Isaac A, Marks DF, Russell DG. An instrument for assessing imagery of movement: the Vividness of Movement Imagery Questionnaire (VMIQ). J Ment Imagery 1986;10(4):23-30.
45. Malouin F, Richards CL, Jackson PL, Lafleur MF, Durand A, Doyon J. The Kinesthetic and Visual Imagery Questionnaire (KVIQ) for assessing motor imagery in persons with physical disabilities: a reliability and construct validity study. J Neurol Phys Ther 2007;31(1):20-9.

46. Gentili R, Han CE, Schweighofer N, Papaxanthis C. Motor learning without doing: trial-by-trial improvement in motor performance during mental training. J Neurophysiol 2010;104(2):774-83.

47. Zijdewind I, Toering ST, Bessem B, Van Der Laan O, Diercks RL. Effects of imagery motor training on torque production of ankle plantar flexor muscles. Muscle Nerve 2003;28(2): $168-73$.

48. Cocks M, Moulton CA, Luu S, Cil T. What surgeons can learn from athletes: mental practice in sports and surgery. J Surg Educ 2014;71(2):262-9.

49. Weiss T, Hansen E, Rost R, Beyer L, Merten F, Nichelmann C, et al. Mental practice of motor skills used in poststroke rehabilitation has own effects on central nervous activation. Int J Neurosci 1994;78(3-4):157-66.

50. Cramer SC, Orr EL, Cohen MJ, Lacourse MG. Effects of motor imagery training after chronic, complete spinal cord injury. Exp Brain Res 2007;177(2):233-42.

51. Grangeon M, Guillot A, Sancho PO, Picot M, Revol P, Rode G, et al. Rehabilitation of the elbow extension with motor imagery in a patient with quadriplegia after tendon transfer. Arch Phys Med Rehabil 2010;91(7):1143-6.

52. Jeannerod M. Mental imagery in the motor context. Neuropsychologia 1995;33(11):1419-32.

53. Lotze M, Montoya P, Erb M, Hulsmann E, Flor H, Klose U, et al. Activation of cortical and cerebellar motor areas during executed and imagined hand movements: an fMRI study. J Cogn Neurosci 1999;11(5):491-501.

54. Lacourse MG, Orr EL, Cramer SC, Cohen MJ. Brain activation during execution and motor imagery of novel and skilled sequential hand movements. Neuroimage 2005;27(3): 505-19.

55. Hanakawa T, Immisch I, Toma K, Dimyan MA, Van Gelderen $P$, Hallett M. Functional properties of brain areas associated with motor execution and imagery. J Neurophysiol 2003;89(2):989-1002.

56. Dechent $\mathrm{P}$, Merboldt KD, Frahm J. Is the human primary motor cortex involved in motor imagery? Brain Res Cogn Brain Res 2004;19(2):138-44.

57. Roth M, Decety J, Raybaudi M, Massarelli R, Delon-Martin C, Segebarth $C$, et al. Possible involvement of primary motor cortex in mentally simulated movement: a functional magnetic resonance imaging study. Neuroreport 1996;7(7): 1280-4.

58. Sharma N, Pomeroy VM, Baron JC. Motor imagery: a backdoor to the motor system after stroke? Stroke 2006;37(7): $1941-52$.

59. de Vries $\mathrm{S}$, Mulder T. Motor imagery and stroke rehabilitation: a critical discussion. J Rehabil Med 2007;39(1):5-13. 
60. Jackson PL, Doyon J, Richards CL, Malouin F. The efficacy of combined physical and mental practice in the learning of a foot-sequence task after stroke: a case report. Neurorehabil Neural Repair 2004;18(2):106-11.

61. Alkadhi H, Brugger P, Boendermaker SH, Crelier G, Curt A, Hepp-Reymond MC, et al. What disconnection tells about motor imagery: evidence from paraplegic patients. Cereb Cortex 2005;15(2):131-40.

62. Moseley GL. Using visual illusion to reduce at-level neuropathic pain in paraplegia. Pain 2007;130(3):294-8.

63. Flor H. Cortical reorganisation and chronic pain: implications for rehabilitation. J Rehabil Med 2003;41(Suppl): 66-72.

64. Gustin SM, Wrigley PJ, Henderson LA, Siddall PJ. Brain circuitry underlying pain in response to imagined movement in people with spinal cord injury. Pain 2010;148(3): 438-45.

65. Gustin SM, Wrigley PJ, Gandevia SC, Middleton JW, Henderson LA, Siddall PJ. Movement imagery increases pain in people with neuropathic pain following complete thoracic spinal cord injury. Pain 2008;137(2):237-44.

66. Roosink M, Robitaille N, Jackson PL, Bouyer $L$, Mercier C. Interactive virtual feedback improves gait motor imagery after spinal cord injury: an exploratory study. Restor Neurol Neurosci 2016;34(2):227-35.

67. Cohen SP, Mao J. Neuropathic pain: mechanisms and their clinical implications. BMJ 2014;348:f7656.

68. Waring WP 3rd, Biering-Sorensen F, Burns S, Donovan W, Graves D, Jha A, et al. 2009 Review and revisions of the international standards for the neurological classification of spinal cord injury. J Spinal Cord Med 2010;33(4):346-52.

69. Kirshblum SC, Burns SP, Biering-Sorensen F, Donovan W, Graves $\mathrm{DE}$, Jha $\mathrm{A}$, et al. International standards for neurological classification of spinal cord injury (revised 2011). J Spinal Cord Med 2011;34(6):535-46.

70. Dworkin RH, Turk DC, Farrar JT, Haythornthwaite JA, Jensen MP, Katz NP, et al. Core outcome measures for chronic pain clinical trials: IMMPACT recommendations. Pain 2005; 113(1-2):9-19.

71. Alexander MS, Anderson KD, Biering-Sorensen F, Blight AR, Brannon R, Bryce TN, et al. Outcome measures in spinal cord injury: recent assessments and recommendations for future directions. Spinal Cord 2009;47(8):582-91.

72. The Joanna Briggs Institute. Joanna Briggs Institute Reviewers' Manual: 2014 edition. Australia: The Joanna Briggs Institute; 2014. 
Appendix I: Data extraction instruments

JBI Data Extraction Form for

Experimental / Observational Studies

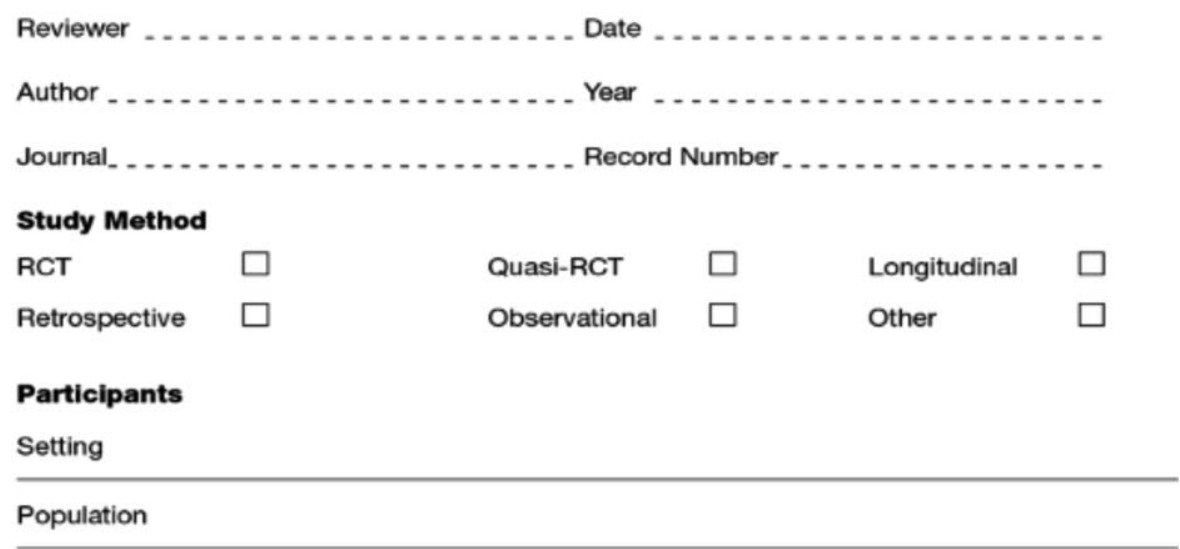

Sample size

Group A

Group B

Interventions

Intervention A

Intervention B

Authors Conclusions:

Reviewers Conclusions:

JBI Database of Systematic Reviews and Implementation Reports 
Study results

Dichotomous data

\begin{tabular}{|l|l|l|}
\hline Outcome & $\begin{array}{c}\text { Intervention ( } \\
\text { number / total number }\end{array}$ & $\begin{array}{c}\text { Intervention ( ) ) } \\
\text { number/total number }\end{array}$ \\
\hline & & \\
\hline & & \\
\hline & & \\
\hline & & \\
\hline & & \\
\hline
\end{tabular}

Continuous data

\begin{tabular}{|l|l|l|}
\hline Outcome & $\begin{array}{c}\text { Intervention ( ) } \\
\text { number/total number }\end{array}$ & $\begin{array}{c}\text { Intervention ( ) } \\
\text { number/total number }\end{array}$ \\
\hline & & \\
\hline & & \\
\hline & & \\
\hline & & \\
\hline & & \\
\hline
\end{tabular}

